\title{
Conocimiento experto y etnografía audiovisual: una propuesta teórico-metodológica
}

\author{
DAFNe MunTANYOLA \\ University of California (UCSD) \\ dmuntanyola@ucsd.edu
}

Recibido: 01.10.2009

Aceptado: 17.052010

\section{INTRODUCCIÓN}

Este artículo explica el cómo y el porqué de la observación audiovisual como herramienta para el análisis cualitativo del conocimiento experto profesional. Como objetivo central, se muestra la pertinencia de una metodología etnográfica en un entorno profesional real. Mediante la grabación en vídeo de los procesos de elaboración y difusión de conocimiento es posible entender y analizar las pautas de comunicación de los médicos/as y enfermeros/as expertas en un entorno hospitalario, parte en mi tesis doctoral (Muntanyola 2008). Los ejemplos comunicativos que se incluyen se han extraído de la observación audiovisual de una unidad de hemodinámica de un hospital público. Su descripción y posterior análisis con el programa Transana muestra como las herramientas audiovisuales pueden hacer visibles dimensiones desconocidas del conocimiento profesional experto. ${ }^{1}$

Más allá de definiciones académicas que dan por sentado el contenido del conocimiento experto (Merton 1988, Berger y Luckmann 1966) un objetivo complementario es que plantear los atributos relacionales de expertos y novicios. El estudio de entornos de trabajo necesita algo más que un análisis cuantitativo de las opiniones y actitudes de los agentes, que es lo que sucede con frecuencia en protocolos de encuestas. Como Ericsson y Lehman (1996) argumentan, para profundizar en la dermis de los procesos de trabajo es necesario desarrollar una metodología de investigación que capte los microprocesos, las manipulaciones instrumentales y las rutinas de trabajo de los actores observados.

${ }^{1}$ Transana) es un programa creado por Chris Fassnacht, cedido a la University of Wisconsin, Madison, y adoptado por el Wisconsin Center for Education Reserach (Centro para la Investigación en Educación). David Woods trabaja allí para mantenerlo y expandirlo.

EMPIRIA. Revista de Metodología de Ciencias Sociales. N. ${ }^{\circ}$ 20, julio-diciembre, 2010, pp. 109-133. 


\section{UN CAMBIO CONCEPTUAL PARA EL ANÁLISIS DE LOS EXPERTOS MÉDICOS EN ENTORNOS DE TRABAJO REALES.}

El primer paso para hablar de la metodología audiovisual y/o digital es dar cuenta de la construcción reflexiva del objeto. Partimos de la idea, ya introducida por Joan Estruch (1992) del falso debate entre metodologías. Estruch habla específicamente de la dicotomía entre metodologías cuantitativas y cualitativas, una cortina de humo para teóricos que se ahogan en datos cualitativos (o que prescinden de toda iniciativa empírica), y empiricistas que pecan de ingenuos o de manipuladores. Por esta razón reclamamos la necesidad de trasladar parte del debate metodológico, en nuestro caso entorno al uso de instrumentos audiovisuales, al nivel teórico, tal como también sugiere Bourdieu (y Wacquant 1992), mediante un modelo integrado de análisis y una estrategia de codificación específica.

\section{Definición del campo del objeto de estudio: el proceso de trabajo experto}

El primer desafío actual para la sociología del trabajo y del conocimiento es el desarrollo de metodologías que puedan captar los aspectos esenciales de los procesos de trabajo expertos, y específicamente de la relaciones entre prácticas y conocimiento por un lado, y entre expertos y novicios por otro (Lozares 2007). Con la etnografía cognitiva tomamos en cuenta las interacciones sociales de los expertos y sus instrumentos de trabajo para entender cómo se produce el conocimiento.

En el campo médico, el ethos define la profesión sobre la base de unos valores morales que implican una actitud, una hexis corporal y hasta una forma de estar del médico/a ante el paciente y entre colegas de profesión. El punto conflictivo nace de la importancia que tiene la escenificación y actuación (staging and acting) en la profesión médica (Luhrmann 2001). Frente a un tipo de conocimiento y explicación de fenómenos absolutamente racional, tanto los expertos como los novicios pasan momentos esquizofrénicos cuando se enfrentan con los problemas reales de su práctica y aprendizaje: «Aprendes mediante equivocaciones y prácticas acompañadas que no son nada consistentes» (Luhrman 2001: 89).El ethos médico incluye el mito del experto como una persona con mayor intuición y con madera de genio singular y aislado del entorno. Este modelo sociocognitivo se reproduce por construcción social. Los jóvenes doctores en fase de aprendizaje describen la práctica médica de forma más pragmática, en el sentido de que la forma de aprender es que te pasen cosas (Becker 1961).

La observación de la práctica médica diaria es crucial para entender los procesos de aprendizaje en el campo. En el lenguaje de Bourdieu (y Wacquant 1992), entender un campo profesional implica conocer los actores que intervienen en los procesos de trabajo. Sus biografías se componen de disposiciones socialmente adquiridas en una trayectoria dada de preferencias, decisiones y gus- 
tos, llamada habitus, o posiciones en la estructura social de la organización. ${ }^{2}$ El discurso o estructura conceptual médica define el conjunto de prácticas asociadas al habitus de expertos y no-expertos. Maquillando el habitus de la distinción (Bourdieu 1979) el proceso de aprendizaje constituye una nueva caja negra para la comprensión del conocimiento experto.

\section{UN MARCO TEÓRICO INTEGRADO PARA EL ANÁLISIS ETNOGRÁFICO-COGNITIVO}

Como veníamos diciendo en la primera sección de este artículo, el debate debe moverse del nivel metodológico al teórico y, por lo tanto, saltar de los instrumentos a las preguntas. La mayoría de los problemas metodológicos surgen de la necesidad de partir de una integración conceptual, lejos de concepciones teóricas cerradas. Por lo tanto, se requiere la producción de una teoría que rompa epistemológicamente con las concepciones dadas por supuesto.

\section{Una alternativa explicativa del conocimiento experto}

La etnografía cognitiva con herramientas audiovisuales es uno de los desarrollos más recientes en la investigación en ciencias sociales, tanto en antropología cognitiva como en ciencia cognitiva (D'Andrade 1995, Hutchins 1995, 2006, Lave et al. 1984, Murphy 2004, Williams 2006, Myers 2008). El adjetivo cognitivo nos separa de la etnografía clásica porque se centra en el proceso de formación de sentido, y no tanto en la perspectiva cultural que da forma a este significado compartido. La etnografía cognitiva que aquí se presenta toma en cuenta las interacciones sociales de los expertos y sus instrumentos de trabajo para entender la producción de conocimiento de una forma corpórea y distribuída (Giere y Moffat: 2003). ${ }^{3}$ Proporcionamos así una explicación gradual y progresiva de las diferencias cualitativas entre los expertos y

${ }^{2}$ Según Bourdieu, «Este habitus se podría definir, en analogía con la gramática generativa de Chomsky, como un sistema de esquemas interiorizados que permitirían engendrar todos los pensamientos, percepciones y acciones características de una cultura, y solamente éstas» (Bourdieu 1967: 142-152). (Traducción de la autora del original francés).

Esta definición temprana de Pierre Bourdieu, poco conocida, parte de dos autores destacados: por un lado, Erwin Panofsky, el primero a conceptualizar el término habitus, y Noam Chomsky, en plena formulación de su concepto de gramática generativa universal. Pierre Bourdieu, como él mismo reconoce, no es el creador del concepto habitus con raíces ya en Aristóteles, pero si es el responsable de su expansión como término sociológico.

${ }^{3}$ Literalmente, embodied (in) significa incorporado, encarnado en. Los autores anglosajones que usan ese término lo usan sin preposición, como una propiedad objetiva del agente, poniendo de relieve su dependencia material, física y social. No obstante, la traducción castellana de encarnada resulta confusa por sus connotaciones religiosas, así que he optado por corpóreo como traducción del original inglés. 
los que todavía no lo son (Dreyfus y Dreyfus 1986, Harper 1987, Collins 1994, Miettinen 2006).

La explicación que adoptamos del trabajo experto constituye una alternativa a la definición atomista de actuación o performance individual. Desde el conocimiento distribuido las capacidades del experto se describen como procesuales y selectivamente verbalizables (D'Andrade 1995, Giere and Moffat 2003, Hutchins 2006, Lozares 2007). La experta se distingue del novicio/a por su capacidad de observación, de anticipación y de la pro-acción, es decir, de preveer las consecuencias de sus actos profesionales. Los expertos/as, en el sentido por el que optamos, seleccionan aquellos elementos del entorno de trabajo que son más necesarios y relevantes para la intervención.

En diversos estudios etnográficos, encontramos ejemplos de cómo los expertos se orientan situacionalmente en todo tipo de entornos profesionales (Benner 1984, Gibbs 2006). ${ }^{4}$ En el campo de la ciencia se han definido los gestos, instrumentos e interacciones verbales que forman parte de la interpretación de datos o resultados científicos (Alac 2005; Myers 2008). En microbiología o en biología molecular, y también en el caso médico, los y las científicas interpretan diariamente la información que proviene de pantallas digitales, imágenes radiológicas y modelos 3D virtuales o analógicos mediante narrativas, metáforas y gestos que forman parte de sus recursos expertos. En el campo artístico tenemos los casos de los músicos (ver Noya y Rodríguez Morató 2010) y de los actores (Noice y Noice 1997). El colectivo de actores desarrolla una estrategia comuna para recordar secuencias de palabras más allá de la estructura por frases o párrafos. Para optimizar sus capacidades memorísticas, los actores y las actrices reconstruyen los diálogos siguiendo un ritmo o pulso. Este flujo de información resulta en un nuevo texto que simplifica el proceso estándar de actuación.

Desde el interaccionismo, Goffman describe con precisión los roles de los administrativos en una institución mental, y explica cómo las narrativas empleadas en situaciones múltiples, más o menos informales, constituyen un cúmulo de valores morales y actitudes, mezclados con detalles materiales y funcionales del flujo de trabajo compartido. Desde la antropología, Goodwin (1994) analiza el juicio y el vídeo testimonial de Rodney King, apaleado por la policía de Los Ángeles por ser negro. Según Goodwin, el experto de la policía gozaba de un prestigio profesional que respaldaba la veracidad de su testimonio, mientras que la víctima sólo se tenía a sí misma para dar la versión de lo sucedido. ${ }^{5}$ King no contaba con el respaldo de todo el cuerpo de policía, ni con la trayec-

4 De forma análoga, los escaladores expertos escogen sus agarres en base a su función, aprovechando al máximo las posibilidades de cada agarre (Gibbs 2006).

5 Chuck Goodwin es uno de los máximos representantes, junto con Christian Heath (\& Hindmarsh 2002) de los estudios de trabajo situados (o workplace studies) con un uso habitual y reflexivo de instrumentos audiovisuales. Influenciados por la perspectiva etnometodológica de Aaron Cicourel (1974), son unos de los precedentes de los estudios etnográficos cognitivos que aquí presentamos.

EMPIRIA. Revista de Metodología de Ciencias Sociales. N. ${ }^{\circ}$ 20, julio-diciembre, 2010, pp. 109-133. ISSN: 1139-5737 
toria profesional del experto psiquiatra ${ }^{6}$. El juicio puso en evidencia la posición diferencial de la víctima y del experto psiquiatra respecto al poder de interpretación del vídeo de la agresión. Por lo tanto, la mayor legitimidad social, en tanto que autoridad científica y policial, del testimonio experto configuró una determinada lectura de las imágenes del video ante el jurado. Su lectura experta fue el resultado tanto de la interpretación situada del video durante el juicio, como de su trayectoria social previa.

En definitiva, la acumulación de resultados etnográficos generaliza la explicación de las habilidades de los profesionales expertos como productos sociales. ${ }^{7}$ Las interacciones y prácticas con los participantes del proceso de trabajo impacta el proceso de decisión. Las cosas sociales o choses sociales resultan ser el producto del pensamiento colectivo y a la inversa. Nuestros cerebros no se han generado ni desarrollado para descubrir la verdad sino para jugar en sociedad (Huizinga 1949). Desde esta perspectiva, el concepto de actuación o performance se convierte en conocimiento experto o expertise en tanto que atributo de grupo, dentro de una determinada jerarquía profesional.

\section{El proceso de análisis etnográfico-audiovisual}

La naturaleza social del conocimiento experto incrementa la complejidad del objeto. El experto no se puede separar del actor social (Labov y Waletzy 1973, Heath y Hindmarsh 2002, Heath 2004, Cicourel 2006a y 2006b). Para entender los constructos cognitivos de los expertos médicos, es necesario mirar hacia el entorno práctico clínico. ${ }^{8}$ Más allá de la interdependencia situacional hacia los instrumentos, nuestra observación determinó la existencia de pautas relacionales constituyentes de los atributos expertos. Las relaciones comunicativas basadas en narrativas profesionales o habladurías técnicas (technical gossip) se dan en entornos de confianza profesional (Knorr-Cetina 1999). Los elementos que componen los procesos cognitivos expertos van más allá del contexto inmediato y, desde luego, también de considerar al individuo como exclusiva unidad de análisis. ${ }^{9}$

${ }^{6}$ Como afirma el antropólogo Goodwin (1994:625) «Dado que las estructuras preceptuales que organizan la interpretación de la cinta se encuentran en la profesión misma y no en el individuo aislado, existe una tremenda asimetría sobre quien puede hablar como experto sobre los eventos en la cinta, y así estructurar una interpretación de ésta» (Traducción de la autora).

7 Tanto desde la teoría de la elección racional como desde la psicología popular (Folk Psychology), el conocimiento experto se ha considerado como una capacidad cognitiva individual (Chi et al 1988, Vanlehn 1989, Simon 1991, Hastie y Dawes 2001, Weiss y Shanteau 2003). No obstante, las categorías de percepción y los esquemas cognitivos profesionales se forman socialmente.

8 «Una persona que domina una tarea especializada no solo cumple una función necesaria en el sistema, sino que también proporciona al grupo una forma de ser, una personalidad, con la cual otros se pueden identificar» (Goffman 2002: 87) (Trad de la autora).

9 Y es que tal como afirman Latour y Woolgar en su más que conocida crítica al proceso científico, como más dura es una ciencia, más social es (Latour y Woolgar 1979). 


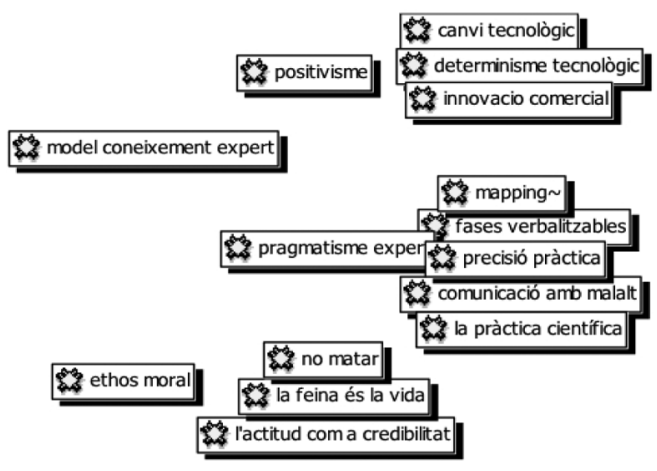

Figura 1. Lista de códigos en ATLAS.ti para la clasificación de los ARE (en catalán).

En definitiva, la estrategia de codificación fue el producto de toma de posición teórica (ver la figura 1) previa al análisis con instrumentos digitales. La codificación ARE basado en hojas de Excel fue el primer paso para procesar la información. En la figura 2, se muestra el modelo de análisis integrado que configuró el diseño de la codificación, según un esquema previo al análisis audiovisual. Analizamos con el programa de análisis cualitativo Transana) las narrativas, blends y gestos observados, y se clasificaron los intercambios entre expertos y no expertos en momentos de actividad recurrente (Activity Recurrent Episodes, o ARE, en Barab, Hay y Yamagata-Lynch 2001). Sólo entonces, en una segunda etapa, como vemos en la figura 3, se utilizó el programa Transana

\begin{tabular}{|c|c|c|c|c|c|}
\hline T.P. & LLOC & $\begin{array}{c}\text { TIPUS } \\
\text { NARRACIÓ } \\
\end{array}$ & ACCIONS & \begin{tabular}{|c||} 
INSTRUMEN \\
TS \\
\end{tabular} & TRANSCRIPCIÓ \\
\hline & ordis & gestio & \multirow{14}{*}{ jordi mira mentre es vesteix } & \multirow{6}{*}{ escopia } & \multirow{9}{*}{$\begin{array}{c}\text { per menjar algo? } \\
\text { posa l'ull a la camara } \\
\text { quan fa que li fa mal? Fa un any mes o } \\
\text { menos...trasllat esforços, cap el gener. Mentre } \\
\text { s'ensabona les mans } \\
\text { no respire pr favor aguante usted ahi.. } \\
\text { digo } 45 \text { min... } \\
\text { asi como esta no respire.. } \\
\text { puedes pasar a craneal...dejar de trabajar ... } \\
\text { comentant imatges i indicant..ahora a poco a } \\
\text { poco... } \\
\text { quieto aqui- amb la ma- mou la màquina just } \\
\text { abans d'avisar-lo }\end{array}$} \\
\hline 27,35 & sala & camara & & & \\
\hline & sala & gossip & & & \\
\hline 29,49 & sala & ordre & & & \\
\hline 30,22 & sala & gestio & & & \\
\hline 31,00 & sala & ordre & & & \\
\hline 31,39 & sala & gossip & & \multirow{2}{*}{$\begin{array}{l}\text { escopia } \\
\text { escopia }\end{array}$} & \\
\hline 33,14 & sala & explic & & & \\
\hline 33,48 & sala & ordre & & escopia & \\
\hline 34,30 & sala & explic & & escopia & comenten imatges despres escopia \\
\hline 35,00 & porta & ordre & & & mireu l'stent, 3 per $24,3-$ \\
\hline 36,40 & sala & gossip & & cateter & posant el cateter per Istent \\
\hline 37,32 & & & & bomba & agafa la bomba \\
\hline 38,10 & sala & explic & & \begin{tabular}{|c||} 
bomba,esco \\
pia
\end{tabular} & $\begin{array}{c}\text { en tensio, jordi deixa anar la bomba, mira i } \\
\text { indica amb el dit, ,, si no lo vemos....una } \\
\text { retirada a tiempo... }\end{array}$ \\
\hline
\end{tabular}

Figura 2. Codificación del vídeo en Excel (en catalán). 


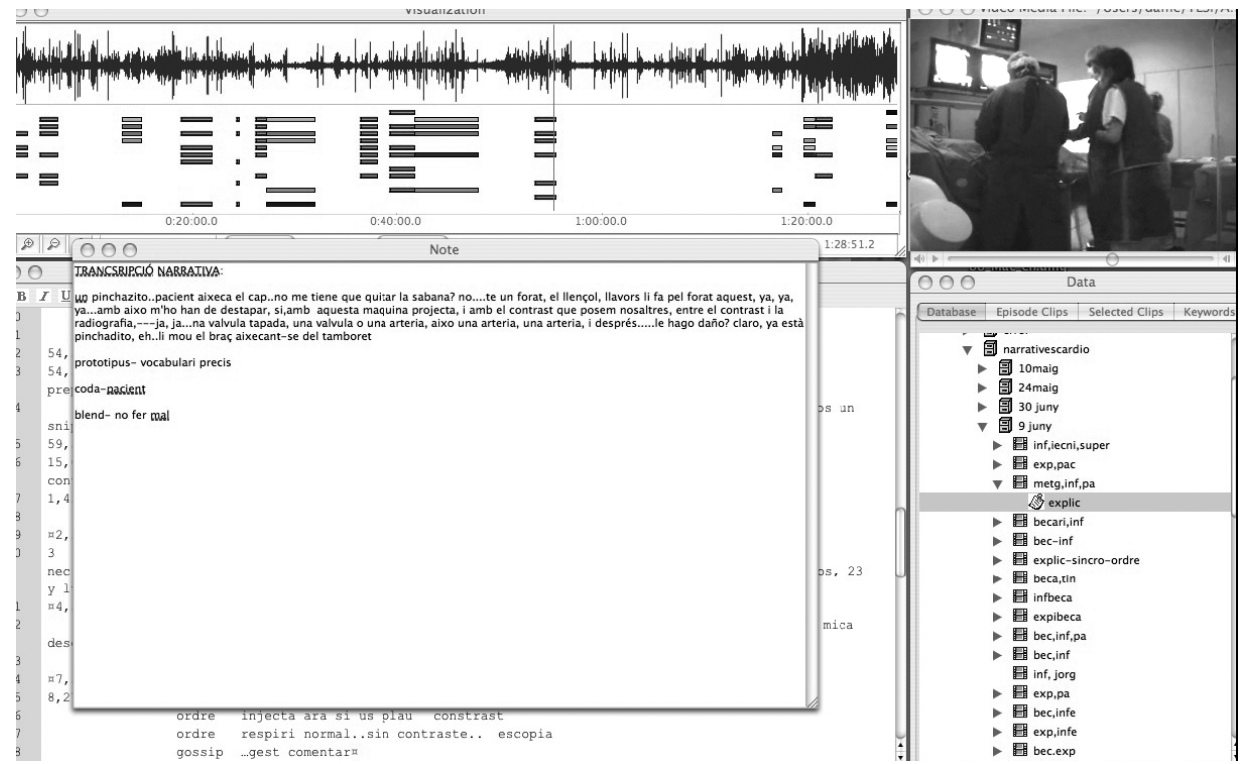

Figura 3. Programa TransanaÒ con fragmentación ARE y análisis de vídeo.

para identificar, etiquetar y asignar a las transcripciones en Excel los fragmentos de vídeo a eventos comunicativos interesantes. Se desarrolló el análisis con Transana > como instrumento central, mientras que las hojas de Excel se usaron como hojas de trascripción y codificación auxiliares.

Las narrativas entre expertos y no-expertos son lugares sociales para externalizar el proceso mental, siguiendo una definición simple de narrativa como «una secuencia de eventos percibidos de forma no-arbitraria» (Toolan en Franzosi 2004). Las narrativas se clasificaron según su contenido narrativo en explicación, argumentación, conversación informal, organización, orden y sincronización. Tales etiquetas fueron extraídas del material audiovisual así como de las notas de campo que se recogieron durante el proceso. En conclusión, mostramos como el análisis audiovisual necesita un modelo fuerte de codificación para no perderse en los datos.

\section{UN CAMBIO METODOLÓGICO PARA LA EXPLICACIÓN DEL CONOCIMIENTO EXPERTO}

Tanto los expertos como los no-expertos son parte de un continuo proceso de resolución de problemas. Las tareas, problemas y requerimientos cognitivos no suceden de forma aislada, sino que están incrustados en pautas comunicativas e interactivas. El conocimiento experto como construcción conceptual no tiene 
agencia, por lo que solo puede explicarse al nivel de procesos de trabajo reales. Necesitamos la observación para recoger los efectos emergentes de pautas comunicativas, ya que los expertos no suelen darse cuenta de las funciones pragmáticas de sus palabras ${ }^{10}$. Más que cualquier otro método cualitativo, la observación lleva la sociología a concentrarse en la contribución de uno u otro agente en relación con la actividad no sólo en su interacción sino también en su totalidad (Valsiner y Van der Veer 2002) ${ }^{11}$. El término «proceso experto» adquiere una dimensión ontológica no sólo como orientación para el investigador, o como figura retórica sobre el papel, sino en tanto que parte de la realidad social observada (Sawyer 2005).

El cambio conceptual para explicar el conocimiento experto llama a introducir una metodología cualitativa de cariz etnográfico y, específicamente, audiovisual. Una historia natural, o natural history, en términos de Cicourel (1974), como la que proponeos en esta tercera sección contribuye a explicar las correspondencias entre las afirmaciones teóricas y los datos empíricos que provienen de la observación audiovisual. Primero, se describe el proceso de entrada al entorno hospitalario. Segundo, se delimitan las dimensiones espaciales, instrumentales y funcionales del proceso médico de intervención. Tercero, se dan ejemplos de la naturaleza comunicativa, multimodal e interactiva del proceso de trabajo experto.

\section{El proceso de entrada al entorno hospitalario}

La entrada de la autora en el campo médico se produjo después de un estudio previo realizado en dos servicios periféricos del mismo hospital: consultas externas y esterilización. Esta primera investigación fue desarrollada por miembros del Grupo de Investigación en Trabajo y Vida Cotidiana (QUIT) (Verd et al 2004, Lozares 2007). En conversaciones posteriores y a raíz de mi tesis doctoral, la directora médica del hospital propuso estudiar la unidad de hemodinámica, como alternativa a la unidad quirúrgica, el núcleo duro de la profesión. Una vez negociado el objeto de la investigación doctoral, la observadora fue bien aceptada. Los profesionales médicos autorizaron el uso de cámaras de video en su entorno profesional. Probablemente tales agentes consideraron la sociología como

${ }^{10}$ En efecto, como Cicourel (1974) y D'Andrade (1995) han puesto de manifiesto, abstracciones como el conocimiento experto sólo se hace operativo cuando bajamos al proceso cognitivo intencional. Simmel lo dice claramente: «Los grandes sistemas y las organizaciones supra-individuales que habitualmente nos vienen a la cabeza cuando pensamos en la sociedad no son nada más que interacciones inmediatas que se dan constantemente, cada minuto, entre personas» (Simmel en Sawyer 2005:199).

${ }^{11}$ Más allá de las aportaciones teóricas que aquí mencionamos, existen otras aportaciones europeas, como la videohermenéutica, que no aparecen el texto por razones de espacio, pero que también parten del carácter holístico de la acción social y de las posibilidades de las herramientas audiovisuales (Knoblauch 2006). 
una disciplina científica claramente subordinada a la médica, por lo que la presencia de la observadora o de las cámaras no resultaba ser molesto ni arriesgado.

La primera fase de la observación se desarrolló entre el 15 de Marzo hasta el 15 de Mayo de 2006. La continua interacción con los actores de la unidad permitió negociar el locus de observación, así como introducir progresivamente las cámaras de vídeo en el entorno de trabajo. En esta fase sólo se tomaron notas de campo. Se detectaron y anotaron las pautas comunicativas que llevaban a tomas de decisión por parte de los expertos, sus movimientos y la ubicación física de los agentes e instrumentos. Se ofreció una descripción general del flujo de trabajo y de la distribución de roles. Finalmente, en esta fase se definió el proceso de intervención básico como aquél que consiste en insertar en el paciente un catéter mediante el cual se inyecta un líquido de contraste que permite ver las imágenes del sistema vascular o cardíaco en la pantalla de la máquina de escopia. ${ }^{12}$

Una vez completada la primera fase de la investigación, comenzó un período de dos meses, desde el 15 de Mayo hasta el 15 de Julio del 2006, en el que se colocaron dos cámaras de vídeo en lugares variables de la unidad (ver figura 1 para las posiciones de las cámaras). Durante ese tiempo la observadora se movió de la sala de ordenadores a la sala de escopia. Este cambio fue percibido positivamente por los miembros del equipo, y permitió una mejor comprensión de las pautas comunicativas entre los profesionales durante la intervención, incluyendo las instrucciones, las narrativas y manipulaciones instrumentales de los médicos y también la tarea asistencial de la enfermeras. Bajo el ojo fijo de la cámara, la observadora se colocó la pesante combinación de plomo que protege de la radiación. Espontáneamente, los médicos y enfermeras verbalizaron comentarios como «Ahora sí que te metes en ello» y «Ahora entenderás qué es esto». Fue como si el acto de ponerse una protección incómoda fuera un indicador del grado de implicación en la investigación. Este segundo período de observación resultó en un mayor grado de familiaridad con el personal de la unidad y más cercanía con algunos miembros del equipo, especialmente enfermeras, con las que la observadora compartió más de una comida ${ }^{13}$. La participación en conversaciones informales fue continua y gracias a la confianza establecida pude concertar y efectuar quince entrevistas fuera del horario de trabajo.

\section{La descripción y distribución de las salas, tareas e instrumentos}

La unidad se compone de tres salas, como vemos en la figura 4. La primera sala a la izquierda es donde los pacientes y sus familias esperan y se recuperan inmediatamente antes y justo después de la intervención. La sala de escopia es la

\footnotetext{
${ }^{12}$ La máquina de escopia es un instrumento radioactivo que realiza unas 60 radiografías por minuto, para hacer aparentes los tejidos blandos.

${ }^{13}$ La distribución de las mesas en el comedor del hospital seguía claramente la jerarquía hospitalaria, con médicos y médicas por un lado, y enfermeras por otra.
}

EMPIRIA. Revista de Metodología de Ciencias Sociales. N. ${ }^{\circ}$ 20, julio-diciembre, 2010, pp. 109-133. ISSN: $1139-5737$ 


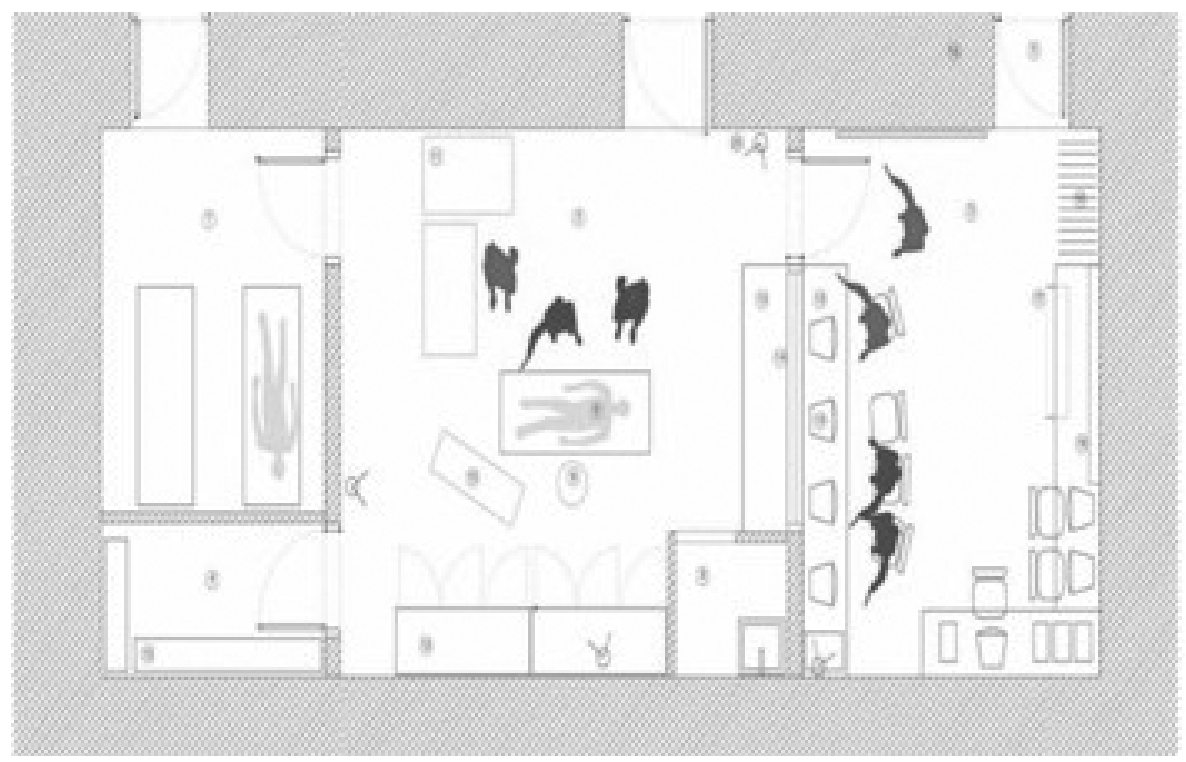

Figura 4. La unidad de hemodinámica en planta, con las tres salas de la unidad, sus agentes, instrumentos y posición de las cámaras.

central y tiene radiación, lo que requiere un acceso restringido, una protección especializada y protocolos detallados de seguridad. La sala de ordenadores, a la derecha, supone una mayor frecuencia de paso, con la presencia de médicos/as y enfermeras, pero también de representantes de casas farmacéuticas. El trabajo de las enfermeras, todas ellas mujeres en este caso, se distribuye de la siguiente forma: una enfermera está constantemente presente ante la pantalla de constantes vitales, la enfermera instrumentista asiste al médico en la sala central de escopia, y una tercera circula entre las tres salas según las necesidades funcionales del sistema ${ }^{14}$.

La sala de ordenadores incluye el armario de chalecos para la protección del personal de la sala central, una pantalla de rayos X para comentar las imágenes de los pacientes, sillas y mesas movibles y seis ordenadores a disposición del personal médico y de enfermería. La sala de escopia incluye el instrumento central, la máquina de escopia con tres pantallas, y una cama móvil. Las paredes están cubiertas con armarios de instrumental especializado que las enfermeras manejan. Un muro de cristal separa estas dos salas. A través de él se hace posible la comunicación verbal y gestual entre los que efectúan la intervención, los médicos que guían los de la sala de escopia, y las enfermeras. La estructura es-

${ }^{14}$ Nos excusamos por los posibles usos inconsistentes del termino medico/a y experto/a. Mientras que en el colectivo de enfermería esta formado personal femenino, el colectivo medico esta formado por 8 hombres y 2 mujeres. 
pacial permite que el personal se mueva entre las tres salas de forma no-regulada. El o la experta en casos estándar permanece en la sala de ordenadores y guía, mediante instrucciones verbales, a los agentes que están en la sala central.

La tecnología está por todas partes (ver las figuras 5 a 8): la maquina de escopia es el instrumento estrelle. Durante la intervención se introducen en el cuerpo del paciente catéteres, guías, globos, y contraste. Además, tenemos todo el material técnico clásico, como agujas, inyecciones, pinzas, vendas, tijeras, y material fungible. El paciente está despierto bajo anestesia local, por lo que es consciente y puede interactuar verbalmente con el personal médico y de enfermería. La dimensión tecnológica configura los atributos de los expertos y su relación con los otros participantes del proceso de trabajo.

Existe una gran variedad de agentes que entran y salen de la sala de ordenadores, lugar donde los expertos guían a los que efectivamente están realizando la intervención. La persistencia de un proceso de aprendizaje continuo llena la sala con estudiantes, residentes, médicos de otras unidades y otros participantes activos. La necesidad de una participación legítima periférica, siguiendo Lave y
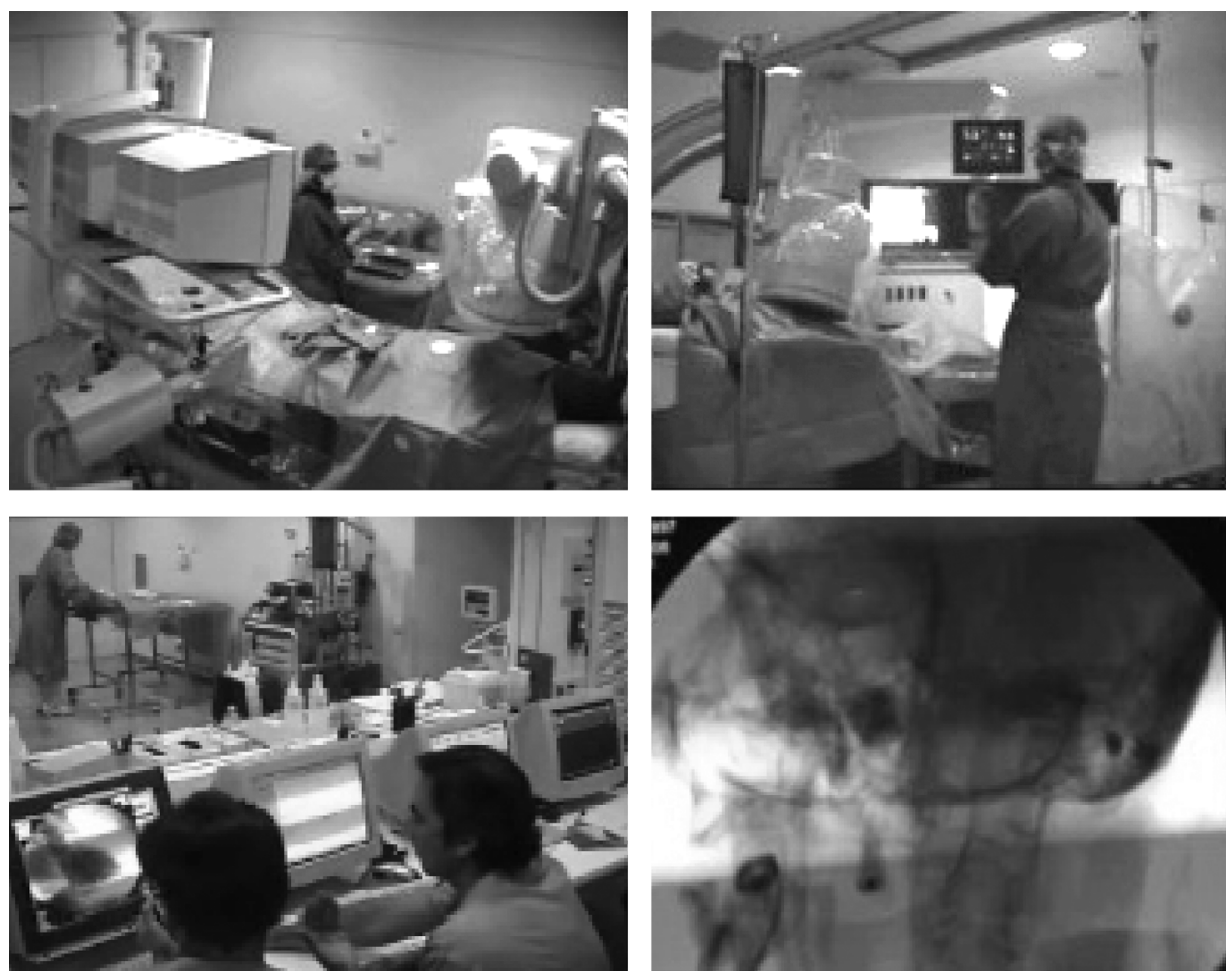

Figura 5-8. Detalles del espacio de hemodinámica: la sala de escopia, la sala de ordenadores, y una imagen de una lesión aórtica. 
Wenger (1991), se hace rápidamente aparente. La observación confirmó que el proceso de aprendizaje del habitus médico es práctico y localmente regulado por el número de años de experiencia del residente (R1-R5) y su participación en las pautas comunicativas del equipo ${ }^{15}$.

\section{Ejemplos de comunicación experta}

Dado que la interacción es la unidad mínima de análisis, vemos que el proceso de conocimiento experto tal como se da en tal unidad es un hecho social física y cognitivamente abierto (Searle 1995). La explicación sociológica del conocimiento experto busca, por lo tanto, principios cognitivos de y a partir de la distribución de conocimiento.

El video es un instrumento idóneo para la captación de elementos comunicativos que pasan desapercibidos en análisis puramente verbales. El uso de cámaras de video favorece la atención al detalle y la conservación del proceso de trabajo como un todo en tanto que hecho social. La observación del flujo de trabajo resulta en dos subprocesos, el médico por un lado, y el de enfermería por otro, con el equipo como unidad de análisis (ver en la figura 9 una muestra del proceso de intervención). El proceso de grabación captó momentos de distribución cognitiva dentro de los dos colectivos, así como marcos de referencia con-

\begin{tabular}{|c|c|c|c|c|c|c|}
\hline TEMPS & FASE & PROCÉS & LLOC & ACCCIONS & IMPREVISTOS & SINCRONITZACIÓ \\
\hline \multirow[t]{11}{*}{ variable } & \multirow{11}{*}{ 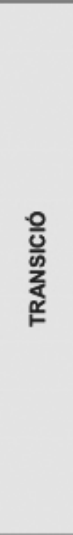 } & \multirow{3}{*}{ 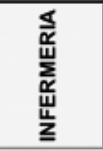 } & \multirow{3}{*}{ ordis } & $\begin{array}{l}\text { supervisora, comercial } \mathrm{i} \text { infermera corbes } \\
\text { parlen de congrés }\end{array}$ & & \\
\hline & & & & $\begin{array}{c}\text { infermera vehicular apunta contrast } \\
\text { administrat per instrumental }\end{array}$ & & \\
\hline & & & & supervisora i comercial conversa informal & & \\
\hline & & \multirow{6}{*}{$\begin{array}{l}\text { 음 } \\
\text { 필 }\end{array}$} & ordis & $\begin{array}{l}\text { adjunt i becari } 2 \text { mapping i diagnosi } \\
\text { definitiu pantalla }\end{array}$ & & \\
\hline & & & sala & $\begin{array}{c}\text { adjunt entra a la sala per explicar al } \\
\text { bacient }\end{array}$ & & \\
\hline & & & vidre & $\begin{array}{c}\text { decisió projecció de metge suggerida per } \\
\text { becari1 }\end{array}$ & & moment decisió fase B \\
\hline & & & \multirow{3}{*}{ ordis } & $\begin{array}{c}\text { mapping conjunt becari1 i metge de la } \\
\text { pantalla }\end{array}$ & & \\
\hline & & & & justificació metge de la diagnosi & & $\begin{array}{l}\text { narrativa justificació: } \\
\text { raonament }\end{array}$ \\
\hline & & & & $\begin{array}{c}\text { diagnosi provisional becari } 1 \mathrm{i} \text { metge } \\
\text { extem }\end{array}$ & & \\
\hline & & \multirow{2}{*}{ 选 틍 } & $\begin{array}{c}\text { habitaci } \\
\delta\end{array}$ & adjunt i supervisora parlen amb la familia & & \\
\hline & & & ordis & $\begin{array}{l}\text { cap confirma tècnic sobre programació } \\
\text { escòpia }\end{array}$ & & \\
\hline
\end{tabular}

Figura 9. La fase de preparación del proceso de intervención por sub-procesos (enfermería, médico y compartido) (en catalán).

${ }^{15}$ La presencia de representantes farmacéuticos es constante. Su objetivo es proveer a los médicos de nuevo material técnico (stents, globos, guías), normalmente mediante conversaciones ociosas, regalitos y comida para el jefe médico de la unidad, y para la jefa de enfermería. 
ceptuales parecidos. En concreto, pudimos especificar sistemas multimodales distribuidos basados en gestos tanto como en palabras (Alac 2005), y encontramos blends, estructuras conceptuales compartidas por todos los miembros del equipo (Fauconnier y Turner 2002).

Las diferencias de grado entre el estado de conocimiento experto y novicio, contextuales y pegadas a la situación social concreta, se encuentran en la aplicación interactiva de blends conceptuales como el de la figura 10, y en la manifestación de gestos como en las figuras 11,12 y $13^{16}$. Este conjunto de elementos tanto gestuales como narrativos dan cuenta de la heterogeneidad y multimodalidad del conocimiento médico experto ${ }^{17}$. La propuesta de los blends responde a la ambición de construir una teoría de las capacidades conceptuales. Los expertos parten de procesos cognitivos mentalmente rápidos, que exigen poca reflexión y que se orientan prácticamente ${ }^{18}$. Los autores de la integración conceptual apuestan, siguiendo a Premack (2004), por una discontinuidad conceptual. Esta operación mental básica está orientada a la acción, por lo que el proceso cognitivo pasa a ser un elemento más del tejido social.
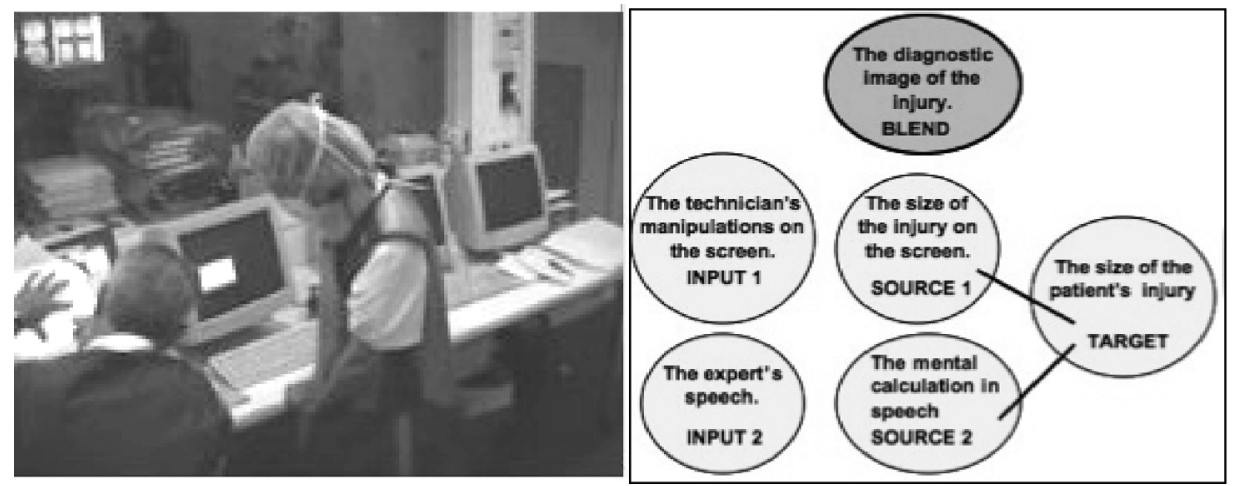

Figura 10. Un sistema interactivo multimodal y el blend calculo diagnostico, basado en gestos, palabras y colas visuales.

${ }^{16}$ Para una descripción exhaustiva de los elementos que diferencian el conocimiento experto en un entorno de trabajo real, específicamente a través de la selección de blends, metáforas, gestos y sistemas interactivos multimodales, ver mi tesis doctoral Muntanyola (2008).

${ }^{17}$ En palabras de uno de los filósofos del conocimiento corpóreo más destacados, Andy Clark, hablar de las habilidades expertas implica: «\{...\} usar un término simple para describir una panoplia de habilidades que varían mucho a nivel tanto cognitivo como físico. La unidad existe solamente en tanto que se considera un conjunto heterogéneo de habilidades cognitivas y físicas con una significación especial para una determinada comunidad de agentes especializados (Clark 1997: 226).

${ }^{18}$ En definitiva, desde el punto de vista evolutivo la capacidad de unir causa y efecto en nuestro acto de comprensión es ventajoso (Facounnier y Turner 2002: 76). 


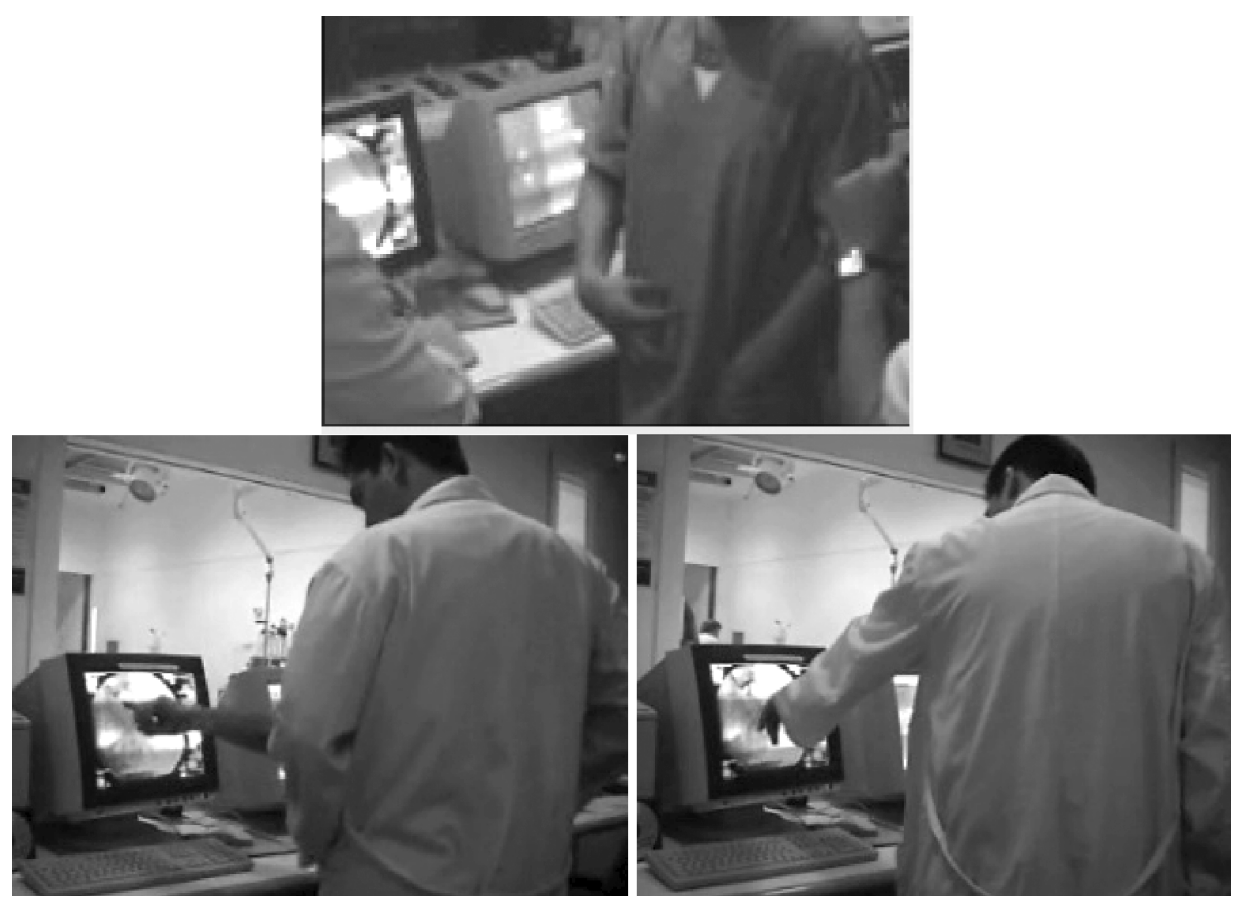

Figuras 11, 12 y 13. Ejemplos de gestos que son parte del conocimiento médico. En la figura 11 un novicio utiliza su propio cuerpo para explicar una lesión, en un gesto corpóreo. Las figuras 12 y 13 muestran una secuencia de acciones en que un médico novicio comenta con otro la extensión de una lesión, señalando la pantalla.

El lenguaje verbal es el elemento comunicativo central del proceso de trabajo experto. Contrariamente al análisis semiótico, el análisis por blends parte de la idea de que los significados se construyen en una acción comunicativa, en el diálogo entre agentes. Por ejemplo, dentro del entorno hospitalario es frecuente que se habla de una carótida para discutir de un paciente con una carótida obstruida, de manera que el espacio real, el del paciente enfermo, se sustituye por una parte de un espacio imaginado, la carótida obturada. Ambos espacios forman parte del dominio real del hospital. En esta metonimia el blend suma dos espacios en un solo dominio, uno contextual, el otro imaginativo. Otros casos son las construcciones contrafactuales (si P, no Q), las condicionales (si P, entonces Q) y las metáforas (como cuando uno de los médicos expertos mira una lesión en la pantalla y la califica de muy bonita)

En la figura 10, la médica experta mide con la ayuda del técnico la magnitud de una obstrucción arterial. La experta realiza el cálculo mental e indica a la enfermera dónde colocar el papel, mientras que ella manipula los instrumentos y realiza el cálculo por escrito. Se trata de un sistema interactivo multimodal (o 
SIM, Alac 2005) en el que múltiples actores focalizan su atención en un instrumento o soporte cognitivo, en este caso, la pantalla con la imagen de escopia. El SIM resulta en una construcción conceptual, que llamamos blend de cálculo diagnóstico. En un primer momento (input 1) las manipulaciones del enfermero constituyen la base para el cálculo, hasta que la experta médica toma el relieve y verbaliza una magnitud final (input 2), tomando la decisión final y ejecutándola, diagnosticando en la sala de intervención. El blend, pues, muestra el carácter interactivo del proceso de trabajo experto, con una fase A de atención y comunicación distribuida y corpórea. No obstante, vemos cómo la fase B o ejecutiva del proceso pertenece a la experta, ya que sitúa con más precisión y rapidez la extensión de la lesión.

El espacio mental de los blends se define como una cadena de pequeños paquetes conceptuales, con el objeto de comprensión y acción (...), conectados por esquemas semánticos llamados marcos (frames) (Fauconnier y Turner 2002:40). El discurso y gestos de los agentes se convierten en anclas materiales de los blends lectura, escritura y gesticulación, de manera que el proceso mental de blending explica todo tipo de fenómenos comunicativos y lingüísticos. La integración conceptual implica un mínimo de 4 espacios: 2 espacios de input, un espacio genérico, y un espacio blended o integrado (Fauconnier y Turner 2002: 279). El proceso diagnóstico que presentamos incluye dos inputs, el discurso de la doctora experta y las manipulaciones del técnico y forma parte del espacio genérico que busca el tamaño real de la lesión, resultando en el blend de cálculo diagnóstico basado en la imagen de la pantalla de escopia.

\section{LAS VIRTUDES ANALÍTICAS Y LOS PUNTOS CONFLICTIVOS EN METODOLOGÍA ETNOGRÁFICO-COGNITIVA}

Numerosas producciones sociológicas desestiman el uso del video digital porque lo consideran el productor de un representación intrusiva o simplificadora de la realidad social. No obstante, optar por una ayuda audiovisual no implica ignorar los aspectos metodológicos de toda observación participante, ni las características propias del vídeo como herramienta de trabajo. Nuestra propuesta considera la observación audiovisual como medio privilegiado para obtener información ${ }^{19}$. La ontología elusiva de los procesos sociales no impide una explicación objetiva de los discursos y prácticas expertas. Como Searle explica en su libro La construcción de la realidad social, el proceso de trabajo en la unidad médica es ontológicamente subjetivo porque depende de convenciones no-arbitrarias como la institución hospitalaria. Esta realidad externa es diferente de la re-

19 Tomaremos una postura epistemológica que se acerca al realismo naturalista (Giere 1988). Este término parte de la certeza podemos explicar científicamente el mundo social con modelos verificables. La calidad naturalista, en oposición al racionalismo estricto, se basa en la capacidad para formular juicios razonables - no necesariamente racionales en los términos de la TER. 
alidad natural, ontológicamente objetiva, que viene con la naturaleza física. Sin embargo, tal distinción no es epistemológica. La realidad social más dura es tan objetiva epistemológicamente como la realidad de pajaritos y plantas (Searle 1995).

Dado que la observación es un proceso corpóreo, en términos contemporáneos, tres elementos entran en juego: la imagen del objeto observado, es decir, el entorno de trabajo y sus agentes; el medio a través del cual el observador percibe actualmente la situación y, finalmente, la perspectiva sociológica de la observadora (Belting 2004). Si añadimos la cámara al proceso de observación, las cosas se complican. Como vemos en la figura 14, la cámara no implica la introducción de un médium en una relación previamente neutral entre la imagen del sujeto y la mirada del etnógrafo: la herramienta audiovisual es un elemento más que se añade a los elementos implícitos en juego.

\section{Las calidades analíticas de la herramienta audiovisual}

A continuación daremos cuenta de los atributos que hacen del vídeo y de la imagen instrumentos insustituibles para la observación de entornos de trabajo. La cámara de vídeo es especialmente útil para la observación de actividades, en oposición al comportamiento captado a través de encuestas o entrevistas. Las notas de campo, por sí solas, no dejan de ser una reflexión de lo sucedido, mientras que el vídeo se sitúa a medio camino entre los datos crudos de la realidad y la reflexión interpretativa.

En primer lugar, la función congelante del vídeo permite la continua re-visualización de lo sucedido, por lo que se incrementa la atención a detalles y a las acciones más inesperadas o aparentemente superfluas del proceso (Valsiner y Van der Veer 2002). El proceso de investigación se puede distribuir entre más de un analista, y la comparación entre diversos procesos de trabajo se hace posible. Ganamos entonces en validez sociológica de la información audiovisual recogida en la observación (Franzosi 2004). La imagen que se mueve nos deja ver hasta el más pequeño detalle de las acciones humanas (Benjamin 1968). El argumento, la acción, se explica más bien como el producto de un momentum resultado de la totalidad de la película. El uso científico de la cámara nos da información deta-
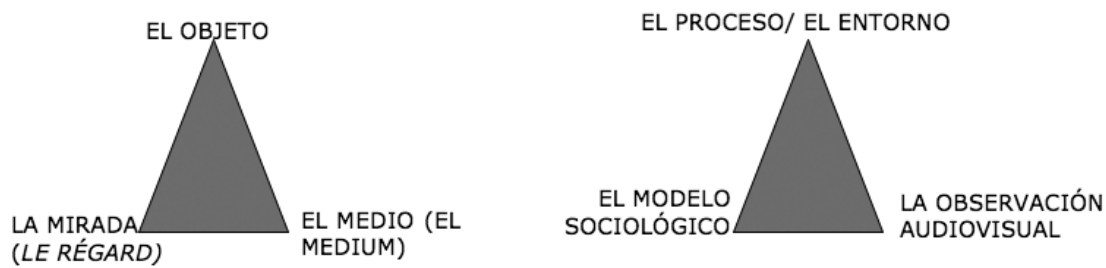

Figura 14. El triangulo de la observación. 
llada sobre gestos, miradas y palabras de los actores observados que serian invisibles al observador más avispado. Continuando con el razonamiento de Brecht, la naturaleza misma de la filmación favorece la perspectiva sociológica, ya que nos invita a contemplar el proceso de intervención médico como un todo en tanto que hecho social.

En segundo lugar, el ángulo de visión de la cámara amplifica la capacidad visual humana. Su profundidad de campo abre el órgano de percepción de la etnógrafa, y así actividades secundarias que son públicamente invisibles adquieren sentido. Como vemos en la figura 15, la preparación de instrumentos médicos por parte de la enfermera instrumental aparece por el visor de la cámara y así esta actividad funcional de enfermería se hace visualmente central.

En tercer lugar, el entusiasmo temprano de la antropología clásica por el vídeo como instrumento de preservación de la totalidad de la actividad social ha sido recientemente reafirmado (Bateson y Mead 1946). Experimentos llevados a cabo desde la psicología del desarrollo han puesto de relieve como la percepción visual parece ser el camino más rápido hacia la acción y la cognición (Kirsh y Maglio 1994). Los lectores más rápidos y eficaces son los que pueden escanear más rápidamente los espacios en blanco entre las palabras impresas; el procesamiento de información se da cuando el ojo se fija en los espacios, y no en las letras (Heath 2004). La atención al detalle intensifica nuestra capacidad cognitiva e incrementa nuestra articulación narrativa. En definitiva, la virtud de literalidad de la cámara nos permite explorar más fácilmente el objeto sociológico.

\section{El riesgo de la reificación y la intrusión}

Dos son los principales riesgos metodológicos de usar medios digitales para la observación: la reificación y la intrusión. La reificación define nuestra ten-

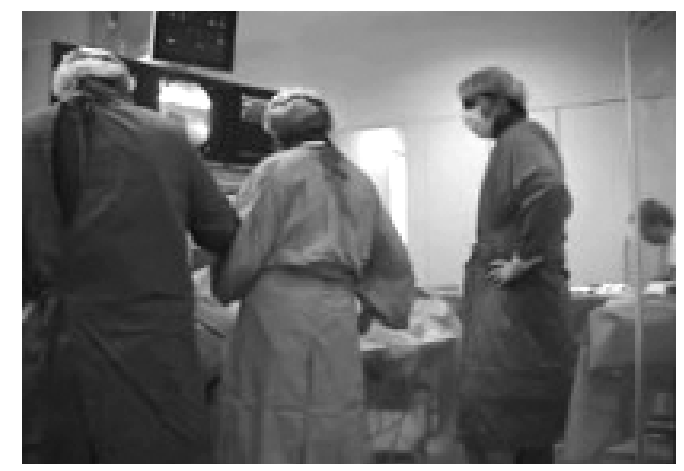

Figura 15. La cámara visibiliza un momento de coordinación entre el médico experto, en postura de espera, y el tándem enfermera experta-médico novicio que realizan tareas de manipulación instrumental. 
dencia a sobrevalorar nuestra capacidad para procesar información. Como Pylyshin (2003) afirma, los científicos sociales caen fácilmente en la falacia escolástica de tomar un evento- tipo (como el ideal de actuación o performance en un experto) como un evento- observado (la práctica de este mismo experto o artista en su entorno profesional). La obtención de imágenes de video puede dar la ilusión de que toda la información que necesitamos «está allí». Sin embargo, las imágenes en video, así como la percepción de un actor individual, son siempre parciales y fragmentadas. Siempre existe el riesgo de perder elementos relevantes para la acción, de «leer» el video escondiendo el carácter selectivo de toda investigación. Determinadas acciones pueden caer de los límites del campo, mientras que otras acciones poco relevantes para el estudio pueden ocupar gran parte de la filmación. Es necesario saber donde colocar la cámara para explicar las pautas comunicativas del conocimiento experto (ver Figura 4 donde se muestra, con triángulos, las posiciones de las cámaras).

Con frecuencia, los documentales televisivos se centran en individualidades $\mathrm{y}$ eventos de tal manera que se esconden los juegos de poder que se encuentran detrás. Como se trata de causas abstractas, no encuentran su sitio delante de la cámara (Bolton 1989). Al mostrar, por ejemplo, los efectos de un tsunami o de un terremoto, el impacto emocional pasa por encima de la causalidad de las acciones, escondiendo sus condiciones de producción. Estos eventos pasan a ser fenómenos inevitables, misteriosos o metafísicos en su origen, sin atribuciones de responsabilidad social. No obstante, estas catástrofes naturales suceden en sociedades con fuertes desigualdades económicas y una distribución mínima de riqueza y recursos naturales, lo que intensifica las consecuencias del desastre sobre la población. De forma paralela al carácter selectivo del documental, una etnografía visual cognitiva no reproduce no la realidad, sino que la re-presenta, se trata de un producto nuevo.

Otra característica negativa de la observación con video es el efecto intrusivo de la observadora como agente externo (Lave et al 1984). Dado que el objeto observado es, de hecho, un sujeto intencional, una observación cualquiera pasa a ser una situación de intervención social. El discurso y la actividad son productos del autoconocimiento (self awareness) del sujeto, lo que lleva a la autoobservación (Lomax y Casey 1998).

\section{La estrategia de la reflexividad}

¿La reificación y la intrusión invalidan el vídeo como instrumento sociológico? Ni la reificación ni la intrusión son efectos exclusivos del medio digital sino que son problemas inherentes al conjunto de técnicas cualitativas y, más concretamente, a las etnográficas. Las decisiones de los médicos, enfermeras, coreógrafo y bailarinas no se dan de forma aislada, sino que están incrustados en pautas comunicativas e interactivas. La triangulación, a través del uso complementario de la percepción visual, la observación con vídeo digital y las entre- 
vistas, resulta ser la estrategia mas eficaz para captar las pautas comunicativas y interactivas.

La cuestión sobre qué debe observarse, y qué no, adquiere características únicas dado el medio digital que utilizamos (Lave et al 1984). La descripción literal nos puede ayudar con el desarrollo de una actitud reflexiva. El sentido de una situación como proceso de negociación tiene que preservarse (Banks 2005). Mientras trabajábamos con datos brutos, y durante todo el proceso de análisis, la socióloga se encontraba en un estado reflexivo, particularmente en el aspecto metodológico. El observador debe detectar, explicar e incluir un constante proceso de negociación entre expertos, no expertos, y la socióloga. El sociólogo o socióloga debe actuar reflexivamente para evitar la reificación empírica e ir más allá de la mera descripción. El proceso de explicitación puede parecer obvio, ya que determinados detalles y experiencias de los procesos pierden interés al ser explicitados, pero es necesario (Knorr Cetina y Cicourel 1981).

Todas las situaciones como las de la figura 16, en la que la observadora pasa por delante de la cámara, pasando a ser parte del proceso observado, son evidencias para comentar. Tal especificidad no es para los pies de página, sino para ser parte del cuerpo de análisis principal. De esta forma, a través de la narrativa descriptiva del análisis podemos distinguir los efectos de la intrusión de los productos del proceso de trabajo. Se trata de otra aplicación de la narración natural (Cicourel 1974) que introducíamos al explicar el proceso de codificación y de entrada. Una historia estructural no requiere una exposición exhaustiva (y cansina para el lector) de todos los datos, pero sí que pide la inclusión de todos los tipos generales obtenidos en cada etapa de la investigación. Cualquier evento inesperado, o bien excepciones a los conceptos habitualmente utilizados, se pueden incluir en la narración final de la investigación.

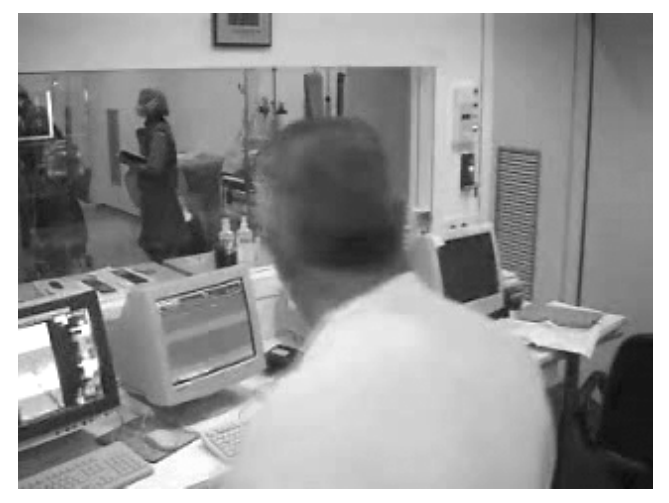

Figura 16. La observadora observada: literalidad y reflexividad. 


\section{CONCLUSIONES}

El debate entre el peso de la palabra y la imagen, o de lo digital y lo analógico, no tiene lugar en procesos de investigación complejos. Este artículo da razones para reformular el debate metodológico sobre el uso científico de la imagen en movimiento. Debemos plantearnos un proceso reflexivo que sale del nivel instrumental para pasar a las preguntas teóricas. En el momento de construir el objeto y en la codificación tomamos decisiones metodológicas que nos empujan hacia uno u otro instrumento de análisis. La bibliografía dominante en el campo de la psicología y de la sociología, particularmente desde la teoría de la elección racional y en inteligencia artificial, localiza el conocimiento experto profesional en un contexto experimental e individualista. Mi propuesta analítica reside en un nuevo modelo alternativo e integrado, basado en una aproximación holista y realista de la recogida de información.

La diferencia de grado entre el estado de conocimiento experto y novicio, tanto de médicos como de enfermeras, no proviene de la aplicación diferencial de determinados mecanismos cognitivos, ni están tan claras como parecen sugerir los textos en psicología popular y desde el sentido común. Las diferencias en la unidad médica de hemodinámica, contextuales y pegadas a la situación social concreta en la que se observaron, se encuentran en la aplicación interactiva de blends conceptuales como el blend de cálculo diagnóstico de la figura 10, y en los gestos y manipulaciones instrumentales en sistemas interactivos multimodales. El conjunto de elementos tanto gestuales como narrativos capturados por la etnografía audiovisual dan cuenta de la heterogeneidad y multimodalidad del conocimiento médico, y sus correspondencias con las pautas comunicativas y de confianza del proceso de trabajo.

Una vez satisfecho el requerimiento de construcción teórica podemos determinar cuándo y cómo utilizar el vídeo y/o los programas digitales de análisis. A través de una aproximación pragmática del conocimiento experto, se han utilizado técnicas cualitativas, como la observación y las entrevistas, en el marco de una etnografía cognitiva. Dado que la objetividad sociológica proviene de la percepción selectiva, pero supuestamente sistemática de la etnógrafa, debemos tener una mirada «entrenada» sociológicamente. Una actitud reflexiva y la inclusión de un relato natural como el que aquí proponemos hace explícito los mecanismos de la investigación y contribuye a los niveles de objetividad y de realismo que aspiramos como científicos sociales.

Es verdad que la etnografía audiovisual es una observación con un medio añadido, la cámara. No obstante, tanto la reificación como la intrusión pueden evitarse o reducirse si se incluye la teoría, la triangulación y/o la reflexividad como parte de la rutina de la investigación. La etnografía audiovisual con cámaras y el programa Transana son útiles para crear un modelo realista y empírico del conocimiento situacional experto. Un cierto nivel de formalización es posible con la codificación y la clasificación de eventos significativos. El siguiente paso en mi agenda de investigación es aplicar este modelo audiovisual a 
otros dominios de conocimiento experto. Mi trabajo actual se centra en una etnografía de una compañía inglesa de danza contemporánea. Incluye el uso de siete cámaras que registran la totalidad del ensayo de una nueva pieza, además de filmar las entrevistas tanto a los bailarines como al coreógrafo. Los avances metodológicos del presente estudio de caso médico pueden mejorar la calidad del grado de formalización, así como de la organización de etnografías audiovisuales en múltiples campos profesionales.

\section{BIBLIOGRAFÍA}

Alac, M. (2005): «From Trash to Treasure: Learning About Brain Images Through Multimodality», Semiotica, 156-1/4, pp.177-202.

BANKS, M. (2005): Visual Methods in Social Research, London, Sage.

BARAB, S., HAY K. y YAMAGATA-LYNCH, L. (2001): «Constructing Networks of ActionRelevant Episodes: An In Situ Research Mehodology», The Journal of the Learning Sciences, 10, pp. 63-112.

Barkow, J., Cosmides. L. y Tooby, J. (1992): The Adapted Mind: Evolutionary Psychology and the Generation of Culture, New York, Oxford University Press.

Bateson, G. y MeAd, M. (1942): Balinese Character, New York, Academy of Sciences.

BeCKer, H. (1961): Boys in White, Chicago, University of Chicago Press.

Belting, H. (2004): Pour une anthroplogie des images, Paris, Gallimard.

Benjamin, W. (1968): Illuminations, Ed. Hanna Arendt, New York, Schocken Books.

Benner, P. (1984): From Novice to Expert: Excellence and Power in Clinical Nursing Practic, Menlo Park, CA, Addison-Wesley.

Berger, P. y LuckMAnN, T. (1966): The Social Construction of Reality: A Treatise in the Sociology of Knowledge. New York, Anchor Books.

Boulding, K. (1961): The Image: Knowledge in Life and Society, Ann Arbor, Michigan University Press.

BouRdieU, P. (1967): «Postface». en Architecture gothique et pensée scholastique. Paris, De Minuit, pp. 230-242.

BourdieU, P. (1979): La distinction, Paris, De Minuit.

BouRdieu, P. y WACQUANT, L. (1992): Réponses: pour une anthropologie réflexive, Paris, Seuil.

Bourdieu, P. (1994a): Raisons Pratiques, Paris, Seuil.

BouRdieu, P. (1994b): «Stratégies de reproduction et modes de domination», Actes de la recherche en sciences sociales, 105, pp.3-12.

Bolton, R. (ed.), (1989): The Contest of Meaning: Critical Histories of Photography, Cambridge, MIT Press.

Carruthers, P., Stich, S. y Siegal, M. (eds.) (2002): The Cognitive Basis of Science, Cambridge University Press.

Chaplin, S. y Walker, J. (eds.) (1997): Visual Culture: An Introduction, Manchester University Press.

ChI, M., GLASER, R. y FARR, M. (eds.) (1988): The Nature of Expertise, Hillsdale, Erlbaum.

ChI, M., BAssoK, M., Lewis, M., Reimann, P. y Glaser, R. (1989): «Self-Explonations: How Students Study and Use Examples in Learning to Solve Problems», Cognitive Science, 13, pp. 145-184. 
Cicourel, A. (1974): Cognitive Sociology, New York, The Free Press.

Cicourel, A. (1990): «The Integration of Distributed Knowledge in Collaborative Medical Diagnosis», en Intellectual Teamwork, New Jersey, Lawrence Erlbaum Associates.

Cicourel, A. (2002): «La gestion des rendez-vous», Actes de Récherche, no 143, p. 3-17.

Cicourel, A. (2006a): «The Interaction of Discourse, Cognition and Culture», Discourse Studies, 8 (1), pp. 25-29.

Cicourel, A. (2006b): «Cogntive/Affective Processes, Social Interaction, and Social Structure as Representational Re-Descriptions: Their Contrastive Bandwidths and Spatio-Temporal Foc», Mind and Society, 5, pp. 39-70.

Clark, A. (1997): Being There: Putting Brain, Body and World Together Again, Cambridge, MIT Press.

Clark, A. (2001): Mindware, New York, Oxford University Press.

Collins, H. (1994): «Dissecting Surgery: Forms of Life Depersonalized», Social Studies of Science, 24, pp. 311-33.

D'ANDRADE, R. (1987): «A Folk Model of the Mind», en Cultural Models in Language and Thought, New York, Cambridge University Press.

D'ANDRADE, R. (1995): The Development of Cognitive Anthropology, Cambridge University Press.

Dreyfus, H. y S. (1986): Mind over Machine, Oxford, Basil Blackwell.

DURKHEIM, E. (1998): Les formes élementaires de la vie religieuse, Paris, Quadrige/PUF.

ERICSSON, K.A. y LeHMANN, A. C. (1996): «Expert and Exceptional Performance: Evidence of Maximal Adaptation to Task Constraints», Annual Review of Psychology, 47, pp. 273-305.

EstruCH, J. (1992): «El conflicte qualitatiu-quantitatiu: un fals problema», Tècniques qualitatives en CCSS. SCS-IEC, pp. 7-16.

FAuCONnIER, G. y Turner, M. (2002): The Way We Think, New Cork, Basic Books.

FETTERMAN, D. (1998): Ethnography, London, Sage.

Feyerabend, P. (1987): «Creativity - A Dangerous Myth», Critical Inquiry, 13,4, pp. 700-711.

Franzosi, R. (2004): From Words to Numbers: Narrative, Data and Social Science, Cambridge, Cambridge University Press.

Garfinkel, H. (1967): Studies in Ethnomethodology, Los Angeles, Polity Press.

GIERE, R. (1988): Explaining Science: A Cognitive Approach, Chicago, University of Chicago Press.

Giere, R. y Moffat, B. (2003): «Where the Cognitive and the Social Merge», Social Studies of Science, 33/2, pp. 1-10.

Gleitman, L. y Gleitman, H. (1992): «A Picture is Worth a Thousand Words, but That's the Problem: the Role of Syntax in Vocabulary Acquisition», American Psychological Association, 1, 1, pp. 31-35.

Goffman, E. (2002): «La distance au rôle en salle d'opération», Actes de Récherche, 3, 143 , pp. $80-87$.

Goodwin, C. (1994): «Professional Vision», American Anthropologist, 96, 3, pp. 603 633.

HARPER, D. (1987): Working Knowledge: Skill and Community in a Small Shop, Chicago University Press.

Hastie, R. y Dawes, R. (2001): Rational Choice in an Uncertain World: The Psychology of Judgment and Decision Making, London, Sage. 
HeATH, S. B. (2004): «Class from the International Graduate Programme (IGP)», Faculty of Social Sciences, Stockholm University, Feb 2004.

HeATH, C. y HindmaRsh, J. (2002): «Analyzing Interaction: Ethnography and Situated Conduct» en Qualitative Research in Action, London, Sage, pp. 99-121.

Huizinga, J (1949): Homo Ludens, London, Routledge.

Hutchins, E. (1995): Cognition in the Wild, Cambridge, MIT Press.

Hutchins, E. (2006): Imagining the Cognitive Life of Things, McDonald Institute, Cambridge University.

KAHNEMAN, D. y TVERSKy, C. (1974): The Concept of Probability in Psychological Experiments. Kluwer Academic.

KIRSH, D. (1991): «Today the Earwig, Tomorrow Man?», Artificial Intelligence, 47, pp. $161-184$

KIRSH, D. (1995): «The Intelligent Use of Space», Artificial Intelligence, 73, pp. 31-68.

KIRSH, D. y Maglio, P. (1994): «On Distinguishing Epistemic From Pragmatic Action», Cognitive Science, 18, pp. 513-549.

KnorR-CETINA, K. (1999): Epistemic Cultures. Cambridge: Harvard University Press.

Knorr-Cetina, K. y Cicourel, A. (eds.) (1981): Advances in Social Theory and Methodology: Toward an Integration of Micro- and Macro - Sociologies, Boston, Routledge \& Kegan Paul.

KnOBlauch, H. (2006): «Videography. Focused Ethnography and Video Analysis», Video Analysis - Methodology and Methods. Qualitative Audiovisual Data Analysis in Sociology. Frankfurt am Main, New York, Lang.

LABOV, W. y WALETZY, J. (1973): «Narrative Analysis: Oral Versions of Personal Experience» en Essays on the Verbal and the Visual Arts, Proceedings of the 1966 Annual Meeting of the American Ethnological Society (AES). Seattle, University of Washington Press.

LAufER, E y Glick, J. (1996): «Expert and Novice Differences In Cognition and Activity: A Practical Work Activity « en Cognition and Communication at Work, Cambridge University Press.

Latour, B. y WoOlgar, S. (1979): Laboratory Life: the Social Construction of Scientific Facts, London, Sage.

Lave, J., Murtaugh, M. y De La Rocha, O. (1984): «The Dialectic of Arithmetic In Grocery Shopping», Everyday Cognition, Harvard University Press, pp. 67-94.

LaVe, J. y Wenger, E. (1991): Situated Learning: Legitimate Peripheral Participation, Cambridge, Cambridge University Press.

LOMAX, H. y CASEY, N. (1998): «Recording Social Life: Reflexivity and Methodology», Sociological Research Online, 3, 2, disponible en https://www.socresonline. org.uk/socresonline/3/2/1.html

LOZARES, C. (eds.) (2007): Interacción, redes sociales y ciencias cognitivas, Granada, Comares.

Luhrmann, T. (2001): Of Two Minds, New York, Vintage Books.

Merton, R. K. (1988): «The Matthew Effect II». Isis, 79, 4, pp. 606-623.

Miettinen, R. (2006): «The Source of Novelty: A Cultural and Systemic View of Distributed Creativity». Sources of Novelty, 15, 2, pp. 173-181.

Montgomery, M. (2006): How Doctors Think, Oxford University Press.

MuntanYola, D. y LOZARES, C. (2004): «El poder del ejemplo», REDES-Revista hispana para el análisis de redes sociales, 10, 5, disponible en http://revista-redes.rediris.es 
MunTANYOLA, D. (2008): El process cognitiu expert: una etnografia d'una unitat hospitalària, Tesis doctoral, Universitat Aut[onoma de Barcelona.

MurPhy, K. M. (2004): «Imagination As Joint Activity: The Case Of Architectural Interaction», Mind, Culture and Activity, 11,4, pp. 267-278.

MYerS, N. (2008): «Molecular Embodiment and the Body-work of Modeling in Protein Crystallography», Social Studies of Science, 38/2, pp. 163-199.

NoIce, T. y NOICE, H. (1997): The Nature Of Expertise On Professional Acting: A Cognitive View, Mahwah, Lawrence Erlbaum Associates.

Noya, J. y Rodríguez Morató, A. (pendiente 2010): en Musyca.: Música, sociedad y creatividad artística. Madrid, Biblioteca Nueva.

PENEFF, J. (1997): «Le travail du chirurgien : les opérations à cœur ouvert», Sociologie du travail, 39, 3, pp.265-296.

Premack, (2004): Is Language the Key to Human Inteligence?, Science, 16, 303, 5656, pp. 318-320.

Pylyshin, Z. (2003): Seeing and Visualizing, Cambridge, MIT Press.

SAWYER, K. (2005): Social Emergence: Societies as Complex Systems, Cambridge University Press.

SeArle, J. (1995): The Construction of Social Reality, New York, The Free Press.

SIMON, H. (1991): «Bounded Rationality and Organizational Learning», Organization Science, 2, 1, pp. 125-134.

Simon, H. y Kaplan, C. (1989): «Foundations of Cognitive Science», en Foundations of Cognitive Science, Cambridge, MIT Press.

Timmermans, S y Berg, M. (2003): The Gold Standard, Philadelphia, Temple Univerity Press.

Turner, M. (2001): Cognitive Dimensions Of Social Science, Oxford University Press.

VAlsiner, J. y VAN Der Veer, R. ( 2002): The Social Mind, Cambridge, University Press.

Verd, J. M., Barranco, O. y Moreno, S. (2007): «El análisis de los procesos de trabajo mediante métodos etnográficos: el caso del trabajo administrativo de consultas externas hospitalarias», Papers, 83, pp. 145-168.

Weiss, D. y Shanteau, J. (2003): «Empirical Assessment of Expertise», Human Factors, 45.

VANLEHN, K. (1989): «Problem Solving and Cognitive Skill Acquisition» in Foundations of Cognitive Science, Cambridge, MIT Press.

Williams, R. (2006): «Using Ethnography to Study Instruction», Proceedings of the 7th International Conference of the Learning Sciences, Mahwah, NJ, Lawrence Erlbaum Associates.

\section{RESUMEN}

El debate entre el peso de la palabra y la imagen, o de lo digital y lo analógico, no tiene lugar en procesos de investigación complejos. Este artículo reclama la necesidad de trasladar parte del debate metodológico, en nuestro caso entorno al uso de instrumentos audiovisuales, al nivel teórico, mediante un modelo integrado del conocimiento experto y una estrategia de codificación. Se presenta además el proceso de entrada y la historia natural del caso de estudio hospi- 
talario, dando cuenta de los entornos de observación, los tipos de análisis y algunos ejemplos ilustrativos del conocimiento experto observado. Finalmente, se apuntan los riesgos y virtudes de la etnografía audiovisual y se presentan posibles estrategias de superación.

\title{
PALABRAS CLAVE
}

Conocimiento experto, metodología audiovisual, conocimiento distribuido, blends.

\begin{abstract}
The debate on the weight of words and images, or else on the digital and the analogical nature, has no place in complex research processes. This paper claims the need to move the methodological debate on audiovisual tools to a theoretical level. We propose an analytical for integration on expert knowledge, together with a codification strategy. We describe the entrance process and the natural history of the hospital unit case study. We also describe the observation setting, the type of analysis performed, and we give some examples of observed expert knowledge. Finally, we pinpoint some risks of audiovisual ethnography and we introduce some possible strategies to overcome them.
\end{abstract}

\section{KEYWORDS}

Expert Knowledge, Audiovisual Ethnography, Distributed Cognition, Blends. 